\title{
Some mechanical properties of aggregates of top soils from the IJsselmeer polders. 1. Undisturbed soil aggregates
}

\author{
A. R. Dexter ${ }^{1}$, B. Kroesbergen ${ }^{2}$ and H. Kuipers ${ }^{2}$ \\ 1 Waite Agricultural Research Institute, University of Adelaide, Glen Osmond, \\ South Australia 5064, Australia \\ 2 Tillage Laboratory, Agricultural University, Diedenweg 20, 6703 GW Wage- \\ ningen, Netherlands
}

Accepted: 19 June 1984

Key-words: clay content, friability, organic matter, polders, porosity, tensile strength, water stability

\section{Summary}

Aggregates were collected from the arable layer at eight different sites in the IJsselmeer polders. The compositions of the soils were determined, and measurements were made of porosities, tensile strengths and water stabilities of undisturbed aggregates.

Porosity was negatively correlated with age of the soils since reclamation. Tensile strength of dry aggregates and water stability were both positively correlated with clay content. The soils had extremely high values of friability. Tensile strength was negatively correlated with porosity. Porosity had no clear influence on water stability.

\section{Introduction}

The purpose of this investigation was to determine some basic mechanical properties of reclaimed soils of different textures. Also, it was of interest to discover whether there had been any significant changes in soil mechanical properties with time since reclamation. This was done by examining soils of three different ages since reclamation.

Although there have been a number of publications describing the development of the soils of the IJsselmeer polders (Smits et al., 1962; Rijniersce, 1983), very little of this work has considered the mechanical properties of individual soil aggregates.

The results presented provide reference data for comparisons with aggregates of other soils from different sites and of different ages. The mechanical properties of artificial, remoulded aggregates of the same soils are considered in detail in Part 2 of this paper (Dexter, Kroesbergen \& Kuipers, 1984). 


\section{Soils}

Soil samples were collected in mid-1982 from the arable layer $(0-200 \mathrm{~mm})$ at eight locations in the IJsselmeer polders. Soils 1 and 2 were from the North East Polder which was reclaimed around 1940; Soils 3, 4 and 5 were from the East Flevo Polder which was reclaimed around 1957; and Soils 6, 7 and 8 were from the South Flevo Polder which was reclaimed around 1968. The composition of the soils is given in Table 1. There were three soils with a low clay content, Soils 2,3 and 8 , all differing in age; two with a medium clay content, 1 and 4, from the two older polders; and three with a relatively high clay content, Soils 5, 6 and 7, from the two younger polders.

A regression shows that the organic matter content, OM (\%), of the soils is positively correlated with the clay content, $\mathrm{C}(\%<2 \mu \mathrm{m})$ :

$$
\begin{aligned}
\mathrm{OM}= & 1.93+0.052 \mathrm{C} \\
& ( \pm 0.36) \quad( \pm 0.012)
\end{aligned}
$$

which accounts for $71.9 \%$ of the variance. The figures in brackets $( \pm)$ in Eq. 1 and in subsequent equations, are the standard errors of the mean fitted parameters.

Table 1. Compositions of the experimental soils.

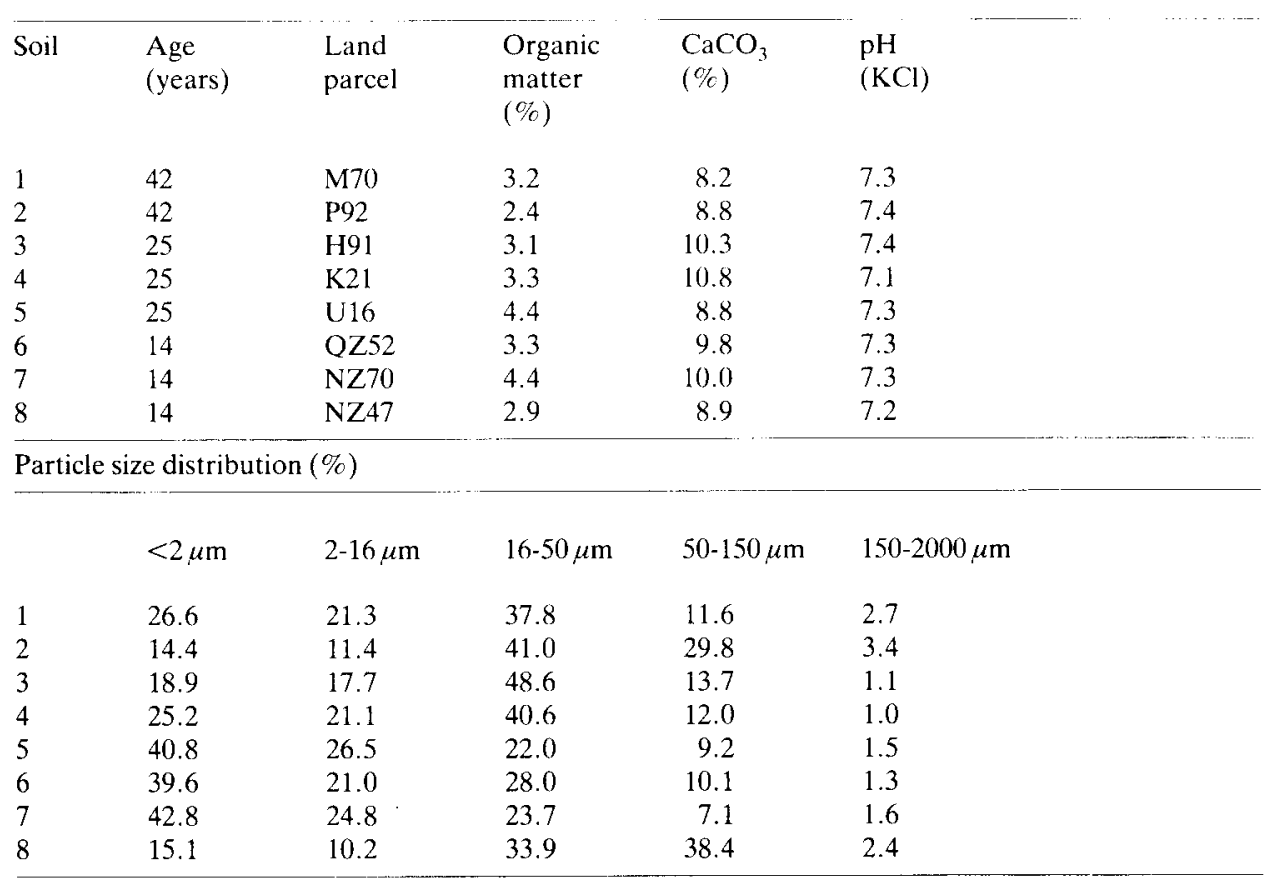




\section{Properties of aggregates of the undisturbed soils}

\section{Aggregate shapes}

Air-dry aggregates of 8.0-9.6 mm diameter of Soils 1, 4 and 6 were collected by sieving. From 21 to 23 aggregates of each soil the major, intermediate and minor principal axis lengths were measured and were expressed as the aspect ratios 1:x:y for each aggregate. The mean ratios for the different soils were 1:0.76:0.64 for Soil 1; 1:0.79:0.66 for Soil 4; and 1:0.80:0.66 for Soil 6. Standard errors of $x$ were $0.027 x$, and standard errors of $y$ were $0.035 y$.

These aspect ratios are close to $1: x: x^{2}$ as reported by Braunack et al. (1979). The mean aspect ratios of the aggregates from the three soils were not significantly different.

\section{Bulk density and porosity}

The bulk density and porosity values for dry, undisturbed aggregates of the experimental soils are given in Table 2 . These values were obtained by the kerosene displacement method of McIntyre \& Stirk (1954). In this method, batches of about 20 100 aggregates are used depending on aggregate size. Three replicate batches were used for each of the three size ranges for each of the eight soils. Table 2 shows only the mean bulk densities of the three size ranges, although all porosity values are given. The standard deviation, $\sigma$ of results from a population of batches, assumed to be normally-distributed, was estimated from the relationship

$$
\sigma=0.886 \vec{\Delta}
$$

where $\bar{\Delta}$ is the mean of the moduli of the differences between pairs of values obtained from different batches within any one soil type. The standard deviation of the population of bulk density values obtained from different batches of any one soil, estimated in this way, was $\sigma=0.008 \mathrm{~g} \mathrm{~cm}^{-3}$.

Table 2. Mean particle specific densities, mean aggregate bulk densities, and porosities of undisturbed aggregates of the experimental soils. The coefficient $b$ and the standard error of $b$ in the last two columns refer to Eq. 3 .

\begin{tabular}{llllllll}
\hline Soil & $\begin{array}{l}\text { Particle } \\
\text { specific } \\
\text { density } \\
\left(\mathrm{g} \mathrm{cm}^{-3}\right)\end{array}$ & $\begin{array}{l}\text { Bulk } \\
\text { density } \\
\left(\mathrm{g} \mathrm{cm}^{-3}\right)\end{array}$ & $\begin{array}{l}\text { Porosity }(\mathrm{v} / \mathrm{v}) \\
\text { Aggregate size range }(\mathrm{mm})\end{array}$ & $\begin{array}{l}\text { Coefficient } \\
b\end{array}$ & $\begin{array}{l}\text { S.E. }(b) \\
n=9\end{array}$ \\
& 2.673 & & $3.4-4.0$ & $4.8-6.8$ & $8.0-9.6$ & & \\
2 & 2.668 & 1.627 & 0.387 & 0.391 & 0.392 & +0.00086 & 0.00038 \\
3 & 2.663 & 1.542 & 0.423 & 0.424 & 0.416 & -0.00149 & 0.00045 \\
4 & 2.665 & 1.632 & 0.396 & 0.386 & 0.381 & -0.00287 & 0.00040 \\
5 & 2.667 & 1.651 & 0.388 & 0.381 & 0.373 & -0.00296 & 0.00035 \\
6 & 2.675 & 1.657 & 0.384 & 0.381 & 0.376 & -0.00169 & 0.00034 \\
7 & 2.660 & 1.625 & 0.390 & 0.391 & 0.386 & -0.00080 & 0.00040 \\
8 & 2.643 & 1.451 & 0.446 & 0.453 & 0.454 & +0.00152 & 0.00057 \\
\hline
\end{tabular}


It can be seen from Table 2 that there were rather clear trends in aggregate porosity, $\eta$, with mean aggregate size, $\bar{D}(\mathrm{~mm})$. This can be described by

$$
\eta=a+b \bar{D}
$$
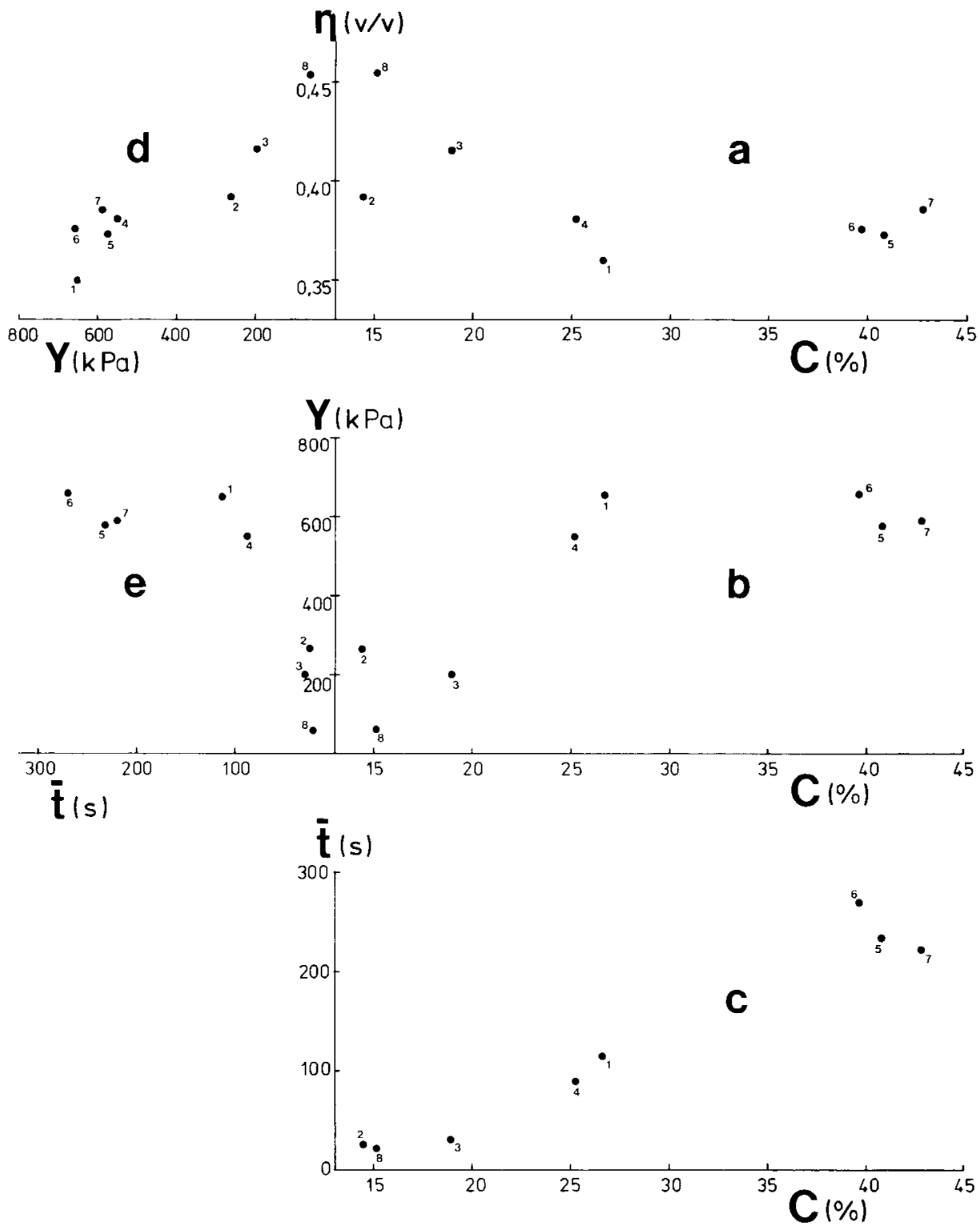

Fig. 1. Relations between clay content $(\mathrm{C}, \%)$, porosity of dry aggregates $(\eta, \mathrm{v} / \mathrm{v})$, tensile strength $(Y$. $\mathrm{kPa})$ and water stability $(\bar{i}, \mathrm{~s})$ for the 8 soils of Table 1 . 
The coefficients, b, in Eq. 3 are also given in Table 2. Six of the coefficients are negative, and two are positive. The two positive coefficients occur for Soils 2 and 8 which have the smallest values of organic matter content, and the smallest values of clay content. However, no statistically significant conclusions about these trends can be drawn. This is probably because aggregate bulk density is influenced strongly by the history of the soil management and by the stress (e.g. compaction) history of the soil.

Porosity values for the mean aggregate size range inTable 2 can be described by

$$
\begin{array}{r}
\eta=0.466-0.0031 \mathrm{C}+0.019(\mathrm{OM})-0.0019 \mathrm{~A} \\
( \pm 0.025)( \pm 0.0006)( \pm 0.009)( \pm 0.0003)
\end{array}
$$

where $\mathrm{C}$ is the clay content (\%), OM is the organic matter content (\%), and $\mathrm{A}$ is the age in years since reclamation. Eq. 4 accounts for $90.6 \%$ of the variance. Graphical analysis (Fig. 1a) shows that the light soils $(2,3,8)$ have a high pore space with a clear influence of age. The medium soils $(1,4)$ have a clearly lower pore space with a smaller influence of age. The heavier soils $(5,6,7)$ have about the same pore space and show no influence of age.

\section{Tensile strength}

Tensile strengths of the soil aggregates were determined by a simple crushing test (Dexter \& Kroesbergen, in press). Firstly, the aggregates were dry-sieved into the $8.0-9.6 \mathrm{~mm}$ size range. For Soils 1,4 and 6 , additional studies were done on the 3.44.0 and $4.8-6.8 \mathrm{~mm}$ size ranges. The aggregates were then oven-dried at $105{ }^{\circ} \mathrm{C}$ for 24 hours. The above size ranges gave mean sieving diameters of $\bar{D}=3.7,5.8$ and 8.8 $\mathrm{mm}$. The mass, $m$, of each individual aggregate was determined by weighing and the polar force, $F(\mathrm{~N})$, required to crack the aggregate between flat, parallel steel plates was measured with a lever-loading device (Dexter \& Kroesbergen, in press). The tensile strength, $Y$, of each aggregate was estimated from

$$
Y=0.576(\bar{m} / \bar{m})^{2 / 3} F / \bar{D}^{2}
$$

Table 3. Tensile strength, $Y$, values of oven-dried natural aggregates of $8.0-9.6 \mathrm{~mm}$ diameter.

\begin{tabular}{lll}
\hline Soil & $\begin{array}{l}\text { Tensile strength } \\
Y(\mathrm{kPa})\end{array}$ & $\begin{array}{l}\text { S.E. }(Y) \\
(\mathrm{kPa})\end{array}$ \\
1 & 654 & 74 \\
2 & 265 & 19 \\
3 & 200 & 28 \\
4 & 550 & 64 \\
5 & 578 & 54 \\
6 & 659 & 72 \\
7 & 590 & 70 \\
8 & 63 & 11 \\
\hline
\end{tabular}


where $\bar{m}$ is the mean mass of aggregates in a batch. The factor $(\bar{m} / m)^{2 / 3}$ reduces the variance resulting from variation of aggregate size within any sieved size range. Eleven aggregates were measured for Soils 1,2 and 8 and twelve aggregates for each of the other soils. The results are given in Table 3 . These results can be described by

$$
\begin{gathered}
Y=2272-5230 \eta+8.0 \mathrm{C}, \mathrm{kPa} \\
( \pm 472)( \pm 1080)( \pm 2.7)
\end{gathered}
$$

which accounts for $91.4 \%$ of the variance. It can be seen that aggregate tensile strength is smaller with increased aggregate porosity and/or smaller clay content. For the light soils $(2,3,8) Y$ is low (Fig. 1b) and there is not much difference between the other soils. For the three light soils a higher pore space goes together with a lower $Y$ value. This is also the general trend in the other soils (Fig. Id). If clay content, $\mathrm{C}$, is omitted, then the regression becomes

$$
\begin{gathered}
Y=3235-7113 \eta, \mathrm{kPa} \\
( \pm 511) \quad( \pm 1299)
\end{gathered}
$$

The relation between $Y$ and $\eta$ for the light soils predicts, for the hypothetical case that zero tensile strength would occur at a porosity of $\eta=0.473$.

Attempts were made to measure the tensile strengths of aggregates in the moist condition. However, with the method used, crushing of moist aggregates occurred progressively, and there was no well-defined crack or end-point to enable an appropriate force, $F$, to be determined for use in Eq. 5 .

\section{Friability}

Friability has been defined by Utomo \& Dexter (1981) as 'the tendency of a mass of unconfined soil to break down and crumble under applied stress into a particular size range of smaller fragments'. They identified friability with the parameter $k$ in the equation

$$
\log _{\mathrm{e}} Y=-k \log _{\mathrm{e}} V+A
$$

which was derived from basic statistical and mechanical considerations by Braunack et al.(1979). In Eq. 8, $Y$ is the aggregate tensile strength as determined above and $V$ is the aggregate volume ( $V=\pi \mathrm{D}^{3} / 6$ for a sphere). $A$ is a constant for a given soil at a given water content. It is readily shown, from an examination of Eq. 5 and 8 , that for spherical particles a value of $k=0$ corresponds to crushing force, $F$, increasing as $(\bar{D})^{2}$, and that a value of $k=0.667$ corresponds to $F$ being independent of $\bar{D}$.

For Soils 1,4 and 6 in the dry condition, values of friability were $k=0.32,0.26$ and 0.29 respectively. These values put these soils into Utomo \& Dexter's 'very friable' category even in the dry state. Utomo \& Dexter (1981) examined two Australian soils with $12 \%$ and $17 \%$ clay and found that the friabilities exhibited maxi- 
mum values at water contents close to the lower Atterberg or Plastic Limits of the soils and were much smaller for the dry soil. It seems possible, therefore, that the friabilities of Soils 1, 4 and 6 examined here may approach the crucial value of $k=$ 0.667 referred to above, when in the moist state.

\section{Water stability}

The water stability of the aggregates was assessed by using the rainfall simulator described by Bouma (1969). This comprises an array of tubular holes through which water drips at a constant rate. In these experiments, the water drops of mass $0.0788 \mathrm{~g}$ fell from a height of $1.0 \mathrm{~m}$ at a rate of 107 drops $\mathrm{cm}^{-2} \mathrm{~min}^{-1}$.

Aggregates of the eight soils were air-dried and sieved into the $4.5-4.8 \mathrm{~mm}$ diameter range. The aggregates were then wetted by placing them on a tension table for $24 \mathrm{~h}$ at a suction of $0.8 \mathrm{~m}$ of water. This suction corresponds to a matric potential of $-7.8 \mathrm{kPa}$. For each soil, 100 aggregates were transferred to a metal plate with circular holes of $4.0 \mathrm{~mm}$ diameter such that a single aggregate was placed over each hole. The metal plate with the aggregates oscillated slowly with a circular movement so that the water drops would not always fall in the same place.

The aggregates were then exposed to the artificial rain. After periods of approximately $5,10,15, \ldots$ seconds the rainfall was stopped and the number $(\%)$ of aggregates remaining on the metal plate was counted. As each experiment pro-

\section{Proportion Surviving}

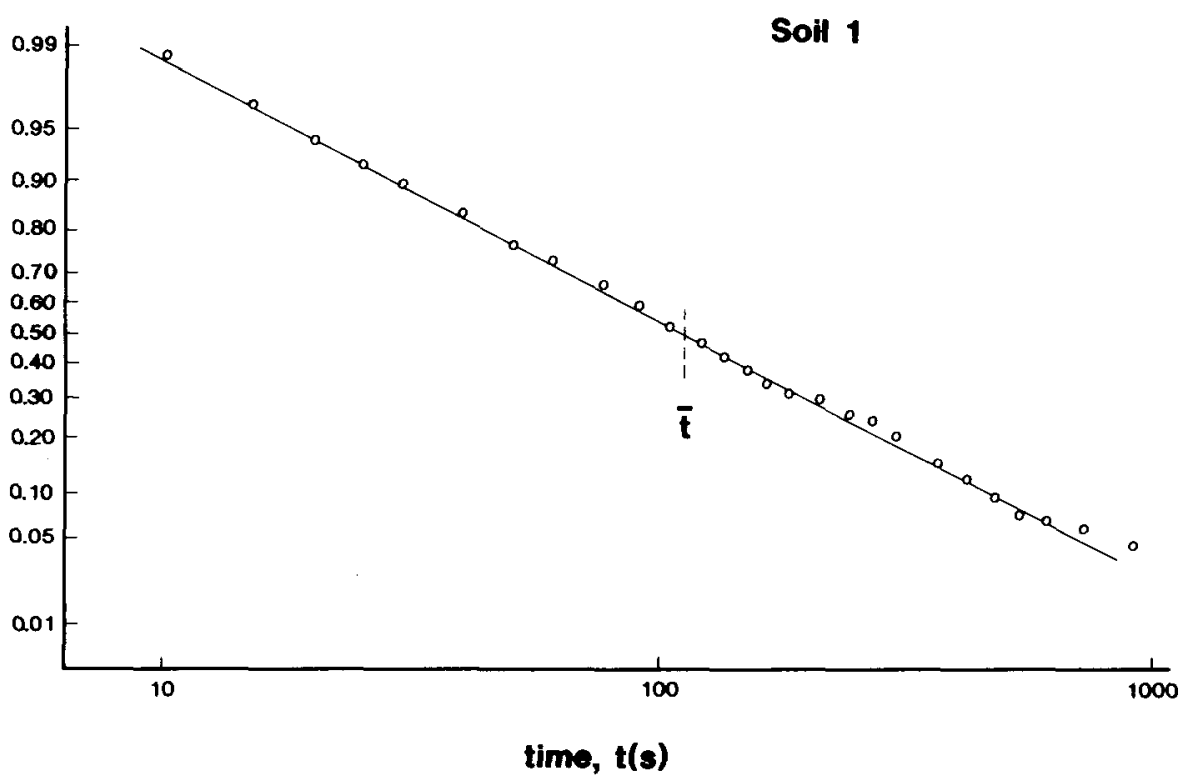

Fig. 2. Water stability curve for Soil 1. Proportions of aggregates surviving are shown as a function of the logarithm of exposure to impact of water drops. 
gressed, the intervals between aggregate counts could be increased. The duration of the experiment ranged from $300 \mathrm{~s}$ for Soil 2 to $1800 \mathrm{~s}$ for Soil 7. Typically, surviving aggregates were counted 25 to 30 times during each experiment. Three replicate experiments were done for each soil.

The proportions $(n / 100)$ of aggregates remaining on the plate were plotted in $\log$ (time)-probability form as shown in Fig. 2. For all except Soil 8, these plots form a good straight line between the 0.9 and 0.1 probability levels. Over this range, the results are well-described by

$$
P=\left(1 / \sigma(2 \pi)^{1 / 2}\right) \exp \left(-(\log t-\log \bar{t})^{2 / 2} \sigma^{2}\right),
$$

where $t$ is the time in seconds, $t$ is the time at which $P=0.5$, and $\sigma$ is the standard deviation of the distribution. For Soil 8 , which was not described in the above way, the $\log ($ time $)$-probability plot appeared to be composed of two linear portions.

Mean values of $\bar{t}(\mathrm{~s})$ and $\sigma$ from the three replicates for the eight soils are given in Table 4. Differences between the replicates were negligible. The values of $\bar{t}$ can be described by

$$
\begin{gathered}
\bar{t}=11.5 \mathrm{C}-58(\mathrm{OM}), \mathrm{s} \\
( \pm 1.0)( \pm 16)
\end{gathered}
$$

which accounts for $97.9 \%$ of the variance. The values of $\sigma$ did not exhibit any particular correlation. A regression of $\bar{t}$ and $\mathrm{C}$ gives:

$$
\begin{gathered}
\bar{t}=8.48 \mathrm{C}-111.4, \mathrm{~s} \\
( \pm 0.81) \quad( \pm 24.3)
\end{gathered}
$$

which accounts for $93.9 \%$ of the variance. The strong influence of clay content on water stability is clearly shown. Eq. 11 suggests that $\bar{t}=0$ for $\mathrm{C}=13 \%$.

Kuipers (1982) obtained a linear relationship between $\log t$ and the percentage of

Table 4. Water stabilities of natural aggregates. $\bar{i}(\mathrm{~s})$ is the time of exposure to the artificial rainfall at which exactly $50 \%$ of the original aggregates survive. The parameter $\sigma$ is the standard deviation of the log-normal survival distribution.

\begin{tabular}{lrl}
\hline Soil & $\bar{t}(\mathrm{~s})$ & $\sigma$ \\
& at $N=50 \%$ & \\
1 & 114 & 0.483 \\
2 & 26 & 0.460 \\
3 & 30 & 0.439 \\
4 & 89 & 0.384 \\
5 & 233 & 0.469 \\
6 & 270 & 0.461 \\
7 & 221 & 0.560 \\
8 & 21 & - \\
\hline
\end{tabular}


soil particles $<16 \mu \mathrm{m}$. When the results in Tables 1 and 4 are plotted in this form, they also give a straight line with a slope similar to that found by Kuipers (1980).

\section{Conclusions}

The only property examined which showed a soil change with age since reclamation was the porosity of the dry aggregates. Eq. 4 shows a statistically significant decrease in porosity with age over the range of ages $14-42$ years of about $2 \%$ porosity in 10 years.

Clay content is clearly the dominant component of the soil composition in determining the examined mechanical behaviour of the soils. Increased clay content is associated with decreased porosity (Fig. 1a), increased aggregate tensile strength (Fig. 1b) and increased aggregate water stability (Fig. 1c).

Aggregate tensile strength shows a strong negative correlation with aggregate porosity (Fig. 1d). No direct effect of soil organic matter content on aggregate tensile strength was found, but there may be a slight indirect effect through the correlation between porosity and organic matter content. The strong negative correlation between aggregate tensile strength and aggregate size yields very high values for the friabilities of these soils, even in the dry state.

It is interesting to compare the dry strengths of the soils, as measured by $Y$, with their wet strengths, as measured by $\bar{t}$ (Fig. 1e). The light soils have low values for $\bar{t}$ and $Y$, and the heavy soils high values. For the intermediate soils, 1 and $4, Y$ is at about the same level as for the heavy soils and $\bar{t}$ is slightly above the value of the light soils. For $Y$ this results in a good correlation with pore space (Fig. 1d). The strong positive relation between $\bar{t}$ and clay content (Fig. 1c) suggests that here pore space is likely to be of minor importance. Because $\bar{t}$ is determined on wet aggregates, pore space at testing was different from pore space of dry aggregates. Swelling of the aggregates of heavy soils, reversed the relation between clay content and pore space from negative to positive, which would suggest lower strengths for heavier soils.

It would be of considerable interest to examine the mechanical properties of aggregates of younger reclaimed soils (e.g. 0-10 years old), where much larger changes with time would be expected as the soils ripened.

\section{Acknowledgement}

A. R. D. would like to thank the Agricultural University, Wageningen, for the award of a Senior Research Fellowship.

\section{References}

Bouma, J., 1969 Micro-structure and stability of two sandy loam soils with different soil management. Agricultural Research Report No 724. Pudoc, Wageningen, $110 \mathrm{pp}$.

Braunack, M. V., J. S. Hewitt \& A. R. Dexter, 1979. Brittle fracture of soil aggregates and the compaction of aggregate beds. Journal of Soil Science 30: 653-667. 
Dexter, A. R. \& B. Kroesbergen, in press. Methodology for determination of tensile strength of soil aggregates. Journal of Agricultural Engineering Research.

Dexter, A. R., B. Kroesbergen \& H. Kuipers, 1984. Some mechanical properties of aggregates of top soils from the IJsselmeerpolders. 2. Remoulded soil aggregates and the effects of wetting and drying cycles. Netherlands Journal of Agricultural Science 32: 215-227.

Kuipers, H., 1982. Processes in physical soil degradation in mechanised agriculture. In: D. Boels, D. B. Davies \& A. E. Johnston, (Eds.). Soil degradation. Balkema, Rotterdam, $286 \mathrm{pp}$

McIntyre, D. S. \& G. B. Stirk, 1954. A method for determination of apparent density of soil aggregates. Australian Joumal of Agricultural Research 5: 291-296.

Rijniersce, K., 1983. A simulation model for physical soil ripening in the IJsselmeerpolders. Flevobericht 203. Rijksdienst IJsselmeerpolders, Lelystad, Netherlands.

Smits, H., A. J. Zuur, D. A. van Schreven \& W. A. Bosma, 1962. De physische, chemische en microbiologische rijping der gronden in de IJsselmeerpolders. [The physical, chemical and microbiological soil ripening in the IJsselmeerpolders.] Van Zee tot Land No 32. Staatsuitgeverij, The Hague, $110 \mathrm{pp}$.

Utomo, W. H. \& A. R. Dexter, 1981. Soil friability. Journal of Soil Science 32: 203-213. 